Journal of English Teaching Adi Buana, Vol. 03 No. 02, October 2018

\title{
THE ENGLISH TEACHERS' INSTRUCTIONAL STRATEGIES TO ASSIST STUDENTS TO MEET THE MINIMUM CRITERION OF MASTERY LEARNING
}

\author{
Jessica Febrina Haryanto \\ Widya Mandala Catholic University Surabaya \\ jessicafebrina3007@gmail.com \\ Agustinus Ngadiman \\ Widya Mandala Catholic University Surabaya \\ ngadiman@ukwms.ac.id
}

\begin{abstract}
This article uncovered the instructional strategies used by Junior High English teacher to assist students to achieve the determined Minimum Criterion of Mastery Learning (MCML) or KKM (Kriteria Kompetensi Minimal). The subjects of the study were 4 English Teachers of Junior High Schools and Senior High Schools in Surabaya. They were assumed to have had enough experiences in teaching EFL to the students. The main instrument of the study was a semi structured questionnaire. There were ten strategies used by English Teachers of Junior High Schools and Senior High Schools to assist their students to meet the Minimum Criterion of Mastery Learning. They are (1) Conducting short review, (2) Teaching step-by-step, (3) Giving a large number of questions,

(4) Giving a large number of questions, (5) Guiding the students' practices,

(6) Checking the students' understanding, (7) Obtaining high success rate.

(8) Providing scaffolds for difficult tasks, (9) Assessing independent practices, and (10) Conducting weekly and monthly review
\end{abstract}

Keywords: Minimum Criterion of Mastery Learning (MCML), strategies

\section{INTRODUCTION}

English in Indonesia has been decided as the first foreign language taught in Junior and Senior High Schools. The primary objective of teaching English is Junior and senior high school is the help students to learn science and technology. Reading is therefore the emphasis skill that students have to master. In addition to reading ability, students are recently expected to be competent in speaking, listening and writing. Linguistic components of English, such as vocabulary, structure and spelling system are expected to be acquired

Since English language teaching in Indonesia has undergone several revision of its curriculum, its objectives also change Competency based curriculum, the one used in 2004. Two years after the implementation of the 2004 curriculum, a new curriculum was introduced, the 2006 KTSP curriculum. And now we have K-13, or 2013 curriculum. Thus, the KTSP curriculum was revised by the 2013 curriculum. Two years later, in 2015, the Ministry of Education announced that the 2013 curriculum should be reevaluated. To deal with that, some schools implemented the KTSP curriculum, and others carry out the 2013 
curriculum. This changing of the curriculum over a short period of time surely causes some controversy and of cause problem in its implementation. Teachers also need to be able to transform the concept of the new curriculum into its classroom practice.

K-13 emphasizes the implementation of scientific approaches with the problem-based learning, discovery-based learning and project-based learning. In general, the learning materials in English are focusing on language competency as a tool of communication in conveying ideas and knowledge. In addition, students are expected to understand, summarize and present the texts in their own language. They are guided to be familiar in organizing systematic, logical and effective texts through exercises of texts building and they are introduced to the rules of the suitable texts in order to avoid ambiguity in the process in making the texts (based on certain situation and condition.

The education system in Indonesia is managed by the Ministry of Education and Culture and the Ministry of Religious Affairs. All citizens are obliged to take twelve years study which consists of six years of elementary school, three years of junior high school and three years of senior high school. Education is constructed to establish a study environment and teaching learning process so that the students could improve and develop their hard skills and soft skills as well as their religious and spiritual level, consciousness, personality, intelligence, behavior, and creativity.

As stated in the teachers and lectures regulation issued in 2005 (Undangundang guru dan dosen 2005), teachers are professional educators, whose main tasks are educating teasing, guiding, training and assessing. Teachers therefore have to adjust their teaching styles, methods, techniques, activities, and strategies based on the objectives stated in the curriculum used. Furthermore, the policies published by the Ministry of Education and Culture state about the Education National Standard which includes the basic standard, the passing standard competency, the standard of educational personnel, the equipment and facility standard, the administration and financial standard, and the educational scoring standard. In the Regulations of the Minister of National Education Indonesia, number 20, 2007, it's mentioned that one of the scoring principles in the curriculum is according to the criterion. Therefore, the first step of conducting assessment and evaluation for the teaching learning outcomes is the fulfillment of the Minimum Criterion of Mastery Learning (MCML).

Minimum Criterion of Mastery Learning or MCML is a criterion of the mastery learning which is determined by Education Level (the School Principal, Vice Principals, and other Educational Personnel) according to the standard competency; the students' characteristics; the subjects' characteristics and complexity; and the condition of the Education Level or the school. According to Directorate of Junior Secondary School Training, in determining the MCML, the School Principal, Vice Principals, and other Educational Personnel should consider several important things; those are counting the numbers of the subject's basic competency in each level in 1 year, deciding the characters value of the students, the materials' complexity and competencies and the equipment and facilities supporting the students in learning at school. The MCML of a subject in a school usually will be the same even if the school applies two different 
curriculums for the teaching learning process of the subject (KTSP and/or Curriculum 2013).

ELT Teachers have the role in the students' learning process. The most important things that the teachers should do are teaching and explaining the materials to the students, guiding and facilitating the students to practice and apply their knowledge of the materials taught and to evaluate the students' learning outcomes. Those three roles are so crucial for the students learning outcomes. The learning outcome then will determine whether the teachers and the students have succeeded in majoring the materials or not. As discussed above that the Minimum Criterion of Mastery Learning (MCML) is the standard used to show whether the students have majored the materials or not after being evaluated. In other words, the teachers should really pay attention on the activities done (teaching, practicing, evaluating) so that the students could meet the MCML

Since assisting the students is so crucial, teachers could use instructional strategies to arrange the strategies in teaching the students inside and outside the classroom. The major independent impact on the student achievement is instructional strategies (Marzano, 2003). Instructional strategies are used to help the teachers to arrange the whole activities in the classroom, to enhance the students' learning progress during the semester or course and to improve the student achievement at the end of the semester or course. Each teacher could construct and arrange his/her instructional strategies by combining particular techniques, methods, activities, media and learning sources based on the students' needs, the allocated time, and the facilities and the equipment provided at school.

According to Alberta (2002), Instructional strategies are the teaching styles, methods, techniques and activities arranged by the teachers to enhance the student achievement inside and outside the classroom. Instructional strategies can motivate students and help them focus attention, organize information for understanding and remembering, and monitor and assess learning.

One of the responsibilities carried by the teachers, especially the EFL teachers, is to support and assist the students in achieving MCML. Each teacher might have his/her own strategies used to assist the students to achieve the MCML. She/he would arrange and organize the activities so that they could increase the students' achievement. Marzano (2003) stated that the major independent impact on student achievement is instructional strategies. Instructional strategies are techniques teachers use to assist the students to become more independent and strategic learners. Besides increasing the students' achievement, it could motivate students and help them to focus their attention, organize information for understanding and remembering and monitor and assess learning. questions

In line with the background above the study tried to answer the following

1. What strategies do the English Teachers use to assist the students to meet the Minimum Criterion of Mastery Learning?

2. What actions do the English Teachers take to treat the students who fail to meet the Minimum Criterion of Mastery Learning?

3. What are the English Teachers' Perceptions of Minimum Criterion of Mastery Learning? 


\section{METHOD}

The 43 respondents of the study were 40 English Teachers of Junior High Schools and Senior High Schools in Surabaya. They were assumed to have had enough experiences in teaching EFL to the students. The main instrument of the study was a semi-structured questionnaire developed by Rosen shine (2010). It was a 10 research-based principle of Instructional Strategies which consists of the following principles: (1) Teaching step-by-step, (2) guiding student practice, (3). Conducting short review, (4) Giving a large number of questions (5) Providing models for the exercises (6) checking student understanding, (7). Obtaining a high success rate, (8) providing scaffolds for difficult tasks, (9) Assessing independent practices, and (10) Conducting weekly and monthly review.

\section{FINDINGS}

\section{Strategies to Assist the Students to Meet the Minimum Criterion of Mastery} Learning

There were ten strategies used by English Teachers of Junior High Schools and Senior High Schools to assist their students to meet the Minimum Criterion of Mastery Learning decided by the school.

\section{Review of previous learning}

$82.5 \%$ or 33 out of 40 respondents gave their students review session for recalling the students' understanding of the materials taught in the previous meeting. The data could be seen in the chart below.

Chart 1: The Review Session Done by the Respondents

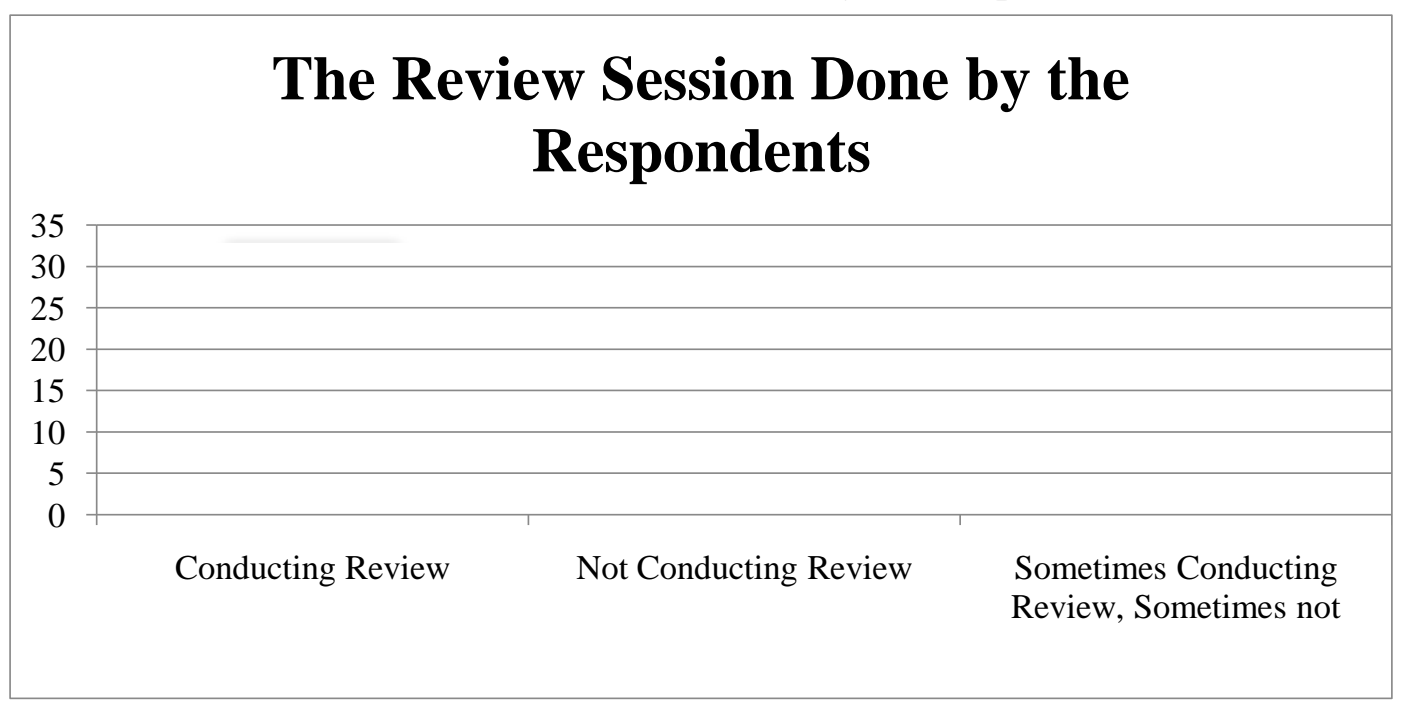

They believed that recalling the students' understanding of the previous materials attracted the students' focus so that they'd be even more ready to accept the new materials. The English teachers also mentioned that they reminded the students about the previous materials since the present materials were the continued section of the previous materials. English teacher didn't give review because the review was given once in a week for the whole topic in one week which has 3 meetings. The other 6 English teachers stated that they reviewed the 
previous materials only if the day's materials were related to the previous materials taught. Since $82.5 \%$ of the respondents did the review, it's proven that reviewing the previous materials at the beginning of the lesson helped the English Teachers to conduct the better learning process.

\section{Presenting new materials step-by-step}

New materials should be introduced and explained one part at one time to the students (Rosenshine, 2010). Teachers first lecture the materials, explain the concepts, do practices with the students, and finally let the students practice independently. The writer then found out that most of the respondents explained a sub-topic of the whole unit in one meeting and directly did the practices with the students. The data is shown in the chart below.

Chart 2: The Ways of Presenting New Materials in 1 Meeting

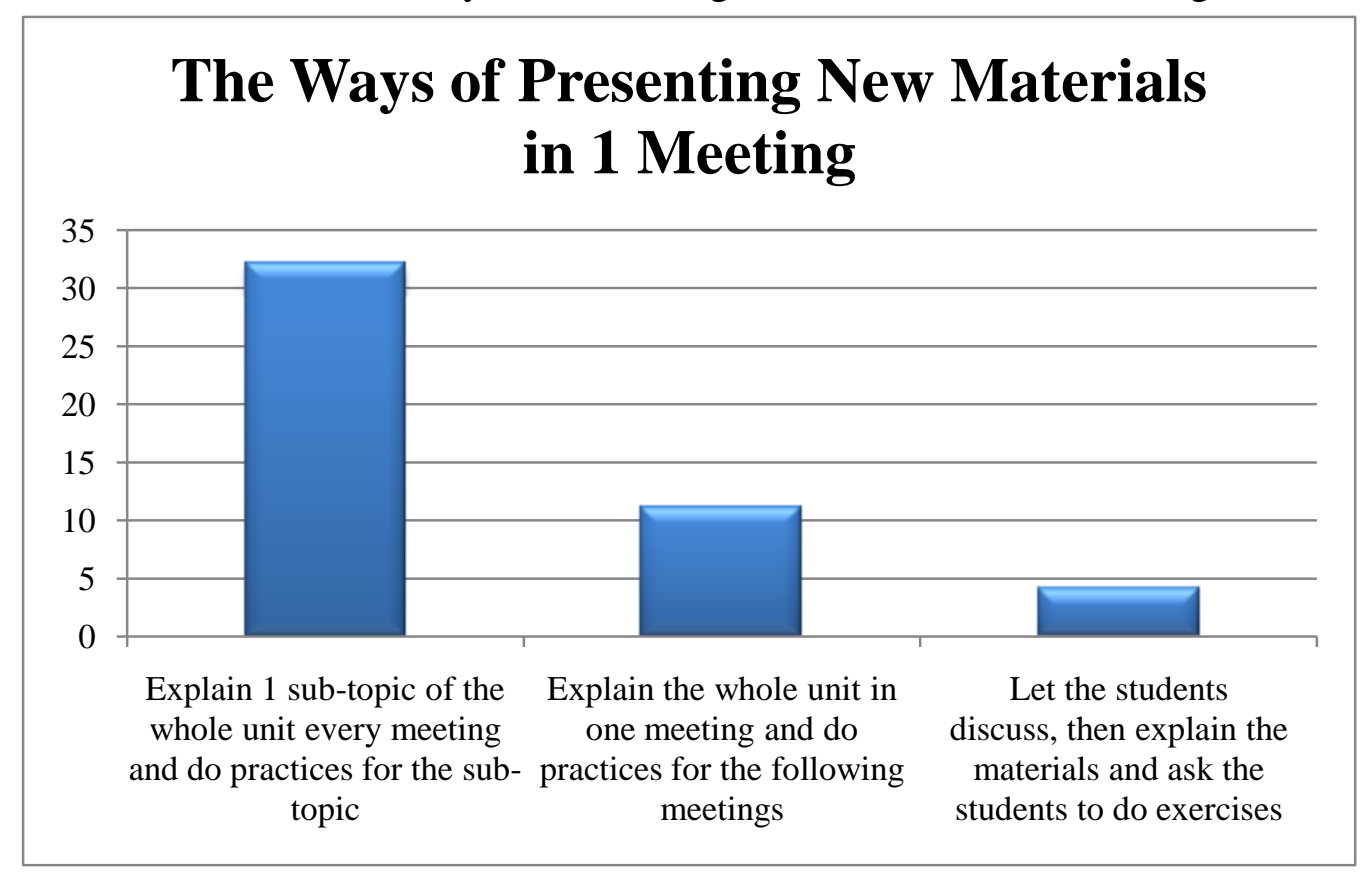

In this question, the respondents could choose more than one activity which was done in explaining the materials in one meeting. The writer collected 47 answers in total and $68.1 \%$ of the answers proved that English teachers usually explained 1 sub-topic of the whole topic in one meeting; then they directed the students to do some exercises about the related materials. As a result, the students got big chances to strengthen their understanding and apply the theories of the materials taught by accomplishing certain practices. $8.5 \%$ of the answers showed that some English teachers preferred to let the students discuss the day's materials first; then the English teachers took only 20-30 minutes of the meeting to explain the materials. The rest of the time was maximally used to train and drill the students with exercises related to the materials. $23.4 \%$ of the answers showed that other English teachers chose to explain 1 unit in one meeting and used the following meetings for the students to practice each sub-topic in detail. 


\section{Giving questions to the students}

Besides practicing the understanding of the materials taught, the students also need to be encouraged to deepen their memory about the materials. A large number of questions should be delivered by the teachers to be able to transfer the materials to the students' long-term-memory. There were varied answers showed up for this question. It could be seen in Chart 3.

Chart 3: The Frequency of the Questions Given to the Students

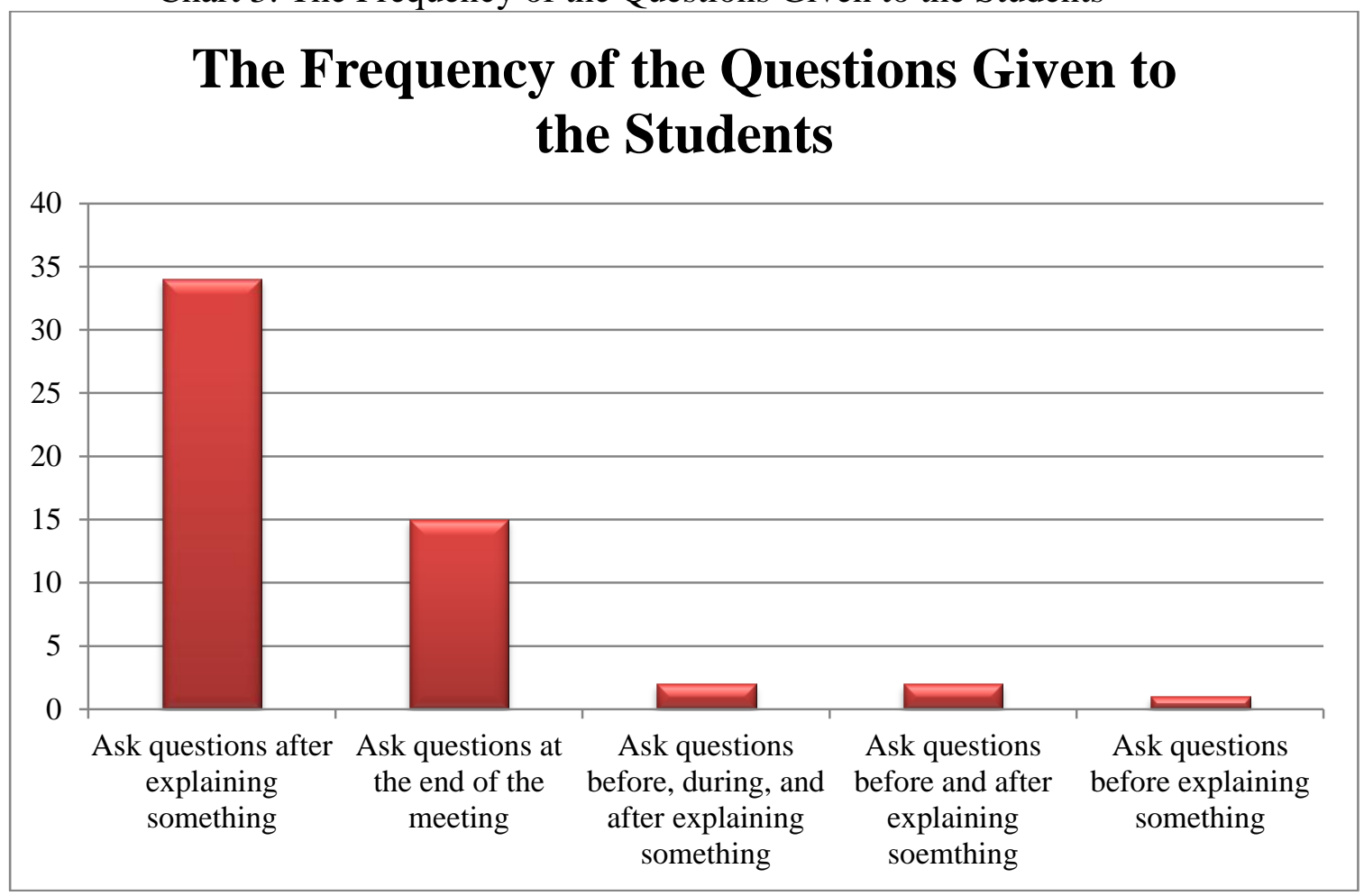

Most of the respondents chose both asking questions after explaining and at the end of the meeting. It showed that the English teachers gave numerous of questions in varied time. From 54 answers, 63\% of them asked questions after explaining something. The English teachers ensured that the students really understood the materials and checked their understandings by giving questions right after the materials were explained. To strengthen the students' memory, $27.7 \%$ of the answers showed that the English teachers delivered the questions again to the students to confirm that they didn't forget about the materials that have been taught. Other five English teachers gave questions more frequently to the students. One of them asked questions before the explanation because the English teacher wanted to discover the students' background knowledge about the materials which would be discussed. The other two English teachers delivered the questions before and after the explanation so that the students could confirm their background knowledge and add or combine the new theory to their knowledge. The rest added the time for delivering the questions during the explanation. It was done because the English teachers wanted to make sure that the students were following their explanation and they could decide to continue explaining the materials or to stop and re-teach the materials. 
Two kinds of questions which were delivered to the students were ICQ (Instructional Check Questions) and CCQ (Concept Check Questions). 38 out of 40 English teachers agreed that they needed both ICQ and CCQ to check the students' understanding.

Chart 4: Types of Questions Given to the Students

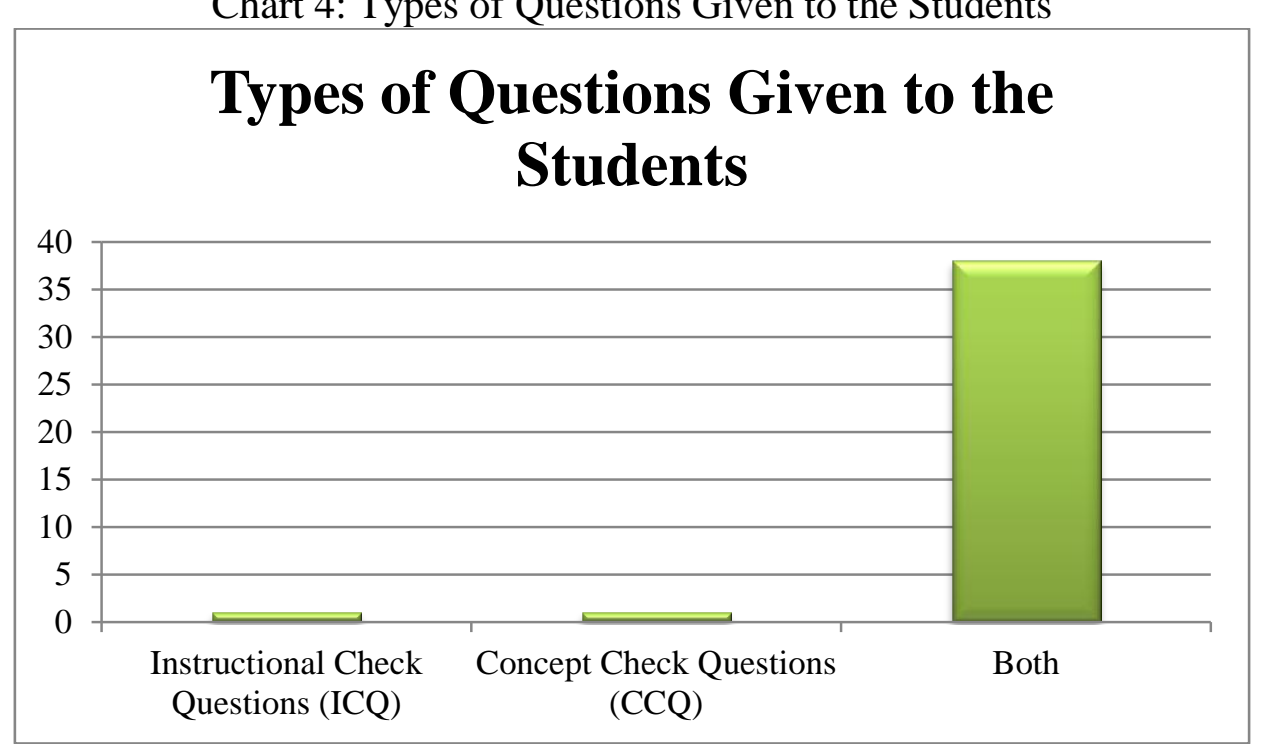

That $95 \%$ of the English teachers delivered both ICQ and CCQ to the students displayed clearly that the importance of ICQ and CCQ were equal. 1 English teacher preferred to deliver more ICQ only and another English teacher preferred to deliver more CCQ only.

\section{Providing Models}

Before asking the students to do exercises independently, the teacher first should give models to the students in doing the exercises. However, not all of the English teachers gave models to the students for their practices.

Chart 5: Models provided for the Students in doing Practices

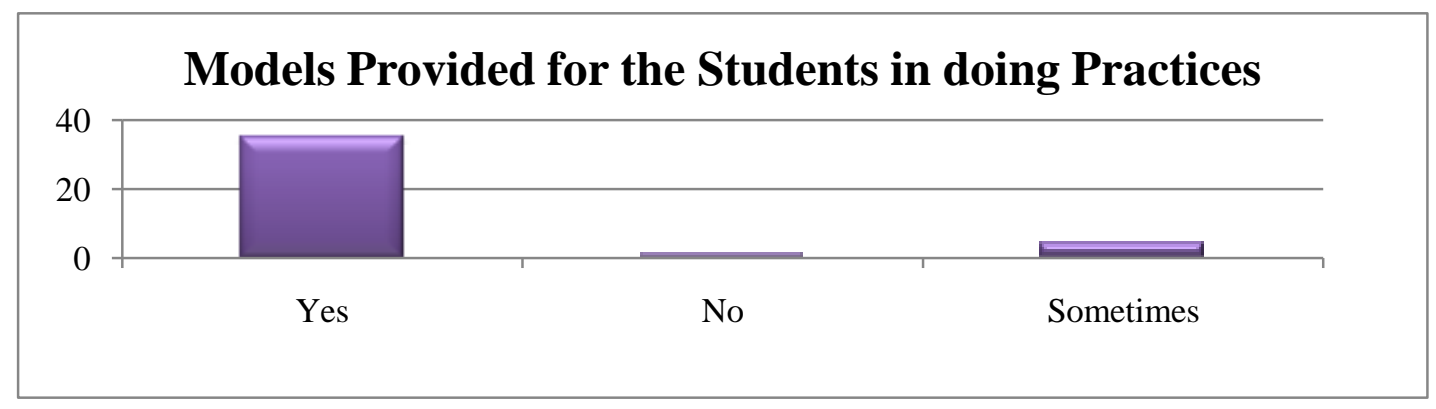

In Chart 6, 87.5\% English teachers had provided models for the students in doing practices. They believed that the students needed help and guide in their first step doing the exercises. Then, they let the students explore by themselves in different practices, even in particular practices which had higher difficulty level. $7.5 \%$ of the English teachers only gave the models when the exercises were too 
difficult for the students or if the students' didn't understand the instructions of the exercises. Only $2.5 \%$ or 1 English teacher didn't provide any models for the students. That was because the instruction of the exercises were made by the teacher and the teacher encouraged the students to explore and find the solution for the exercises in groups/peers. The teacher believed that the students would learn much more when they could solve the problems in the exercises by themselves rather than being modeled.

Chart 6: Ways of Providing Models

\begin{tabular}{|c|c|c|c|}
\hline \multicolumn{1}{|c|}{ Ways of Providing Models } \\
35 \\
25
\end{tabular}

The respondents could choose more than one answer so the writer could collect 72 answers in which $44.4 \%$ of the answers showed that the English teachers preferred to do the exercises together with the students as the model in doing the exercises. They knew that the students would understand more if their first step was modeled well and the students felt more comfortable when they could learn together with their teacher. $36 \%$ of the answers displayed that the English teachers also gave correctly answered exercises to the students so that the students could compare their own answers with the correctly answered exercises. In this way, the students did self-check towards their works. $15.3 \%$ of the answers showed that the English teachers still used the teacher-centered teaching style where the students focused on the teacher's explanation about the exercises for a while before they did the practices by themselves.

The other 3 English teachers mentioned their own activities in providing models for the students. 1 of them liked to ask the students to do projects related to the materials, in which the students could do it in groups and discussed it with their friends. Another one liked to invite the smartest student to come in front of the class to demo the way he/she did the exercises. The teacher believed that the other students felt more encouraged to be able to do the exercises like their friend coming in front. The rest liked to give a solution or a result of the problems in the exercises without any models on how the students could find that result. Then, the 
teacher encouraged the students to discuss and find the process to reach the result or the solution for the problems by themselves.

\section{Guiding student practice}

While the students were practicing independently, the teachers should guide and monitor the students' works. There were so many ways in guiding and monitoring the students, but all of the respondents agreed to walk around the classroom to monitor the students' work.

Chart 7: Ways of Guiding the Students in doing Practices

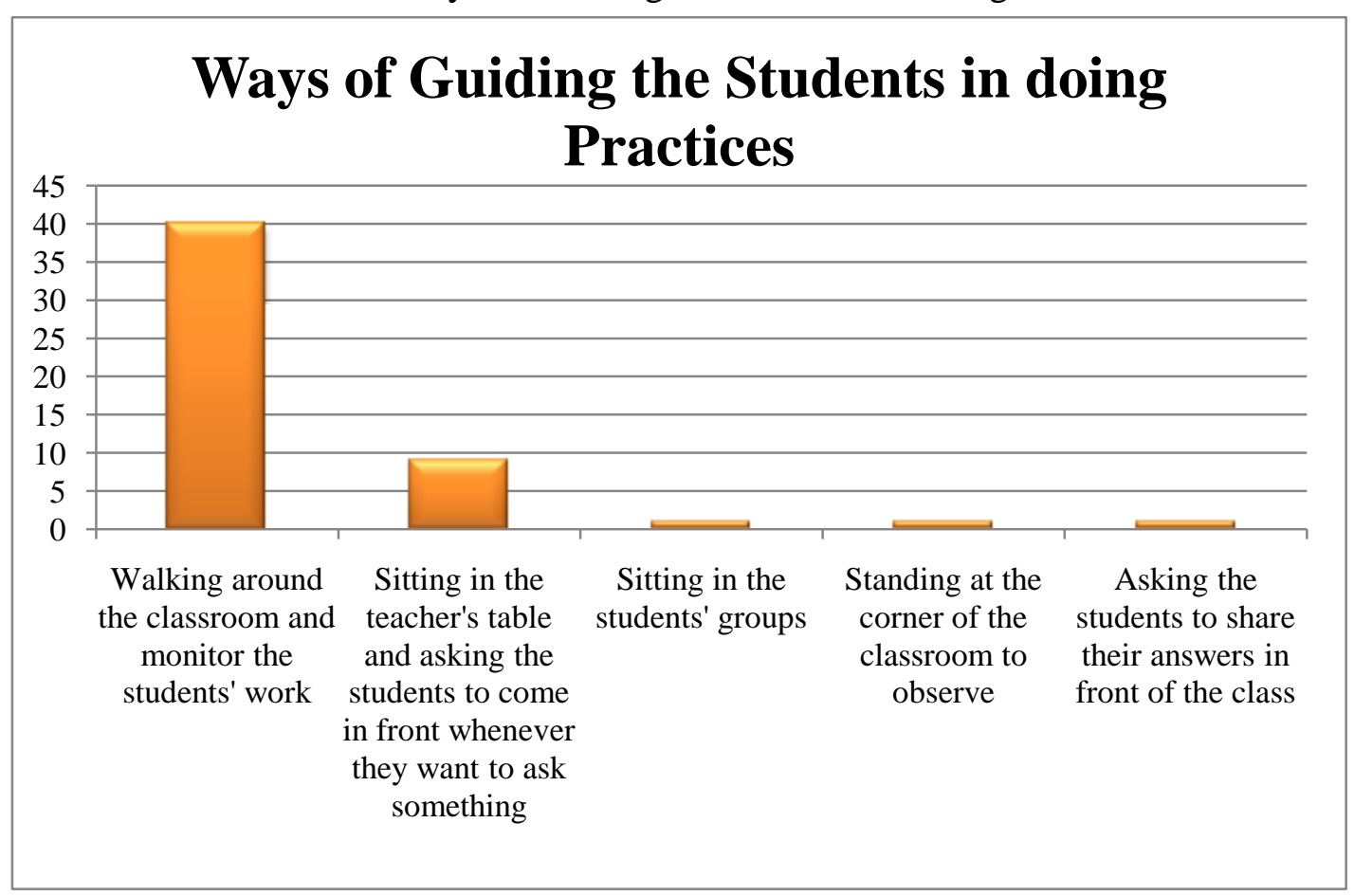

As mentioned before, all of the respondents agreed that they walked around the classroom while the students were practicing, monitored their works, and became ready whenever the students asked for help. The English teachers became more flexible to come to whoever students asking for supports in doing the exercises. However, $17.3 \%$ of the answers also showed that the English teachers sometimes preferred to sit in front of the teacher's table to monitor the students and wait for the students to come in front and ask for help. This also encouraged the students' self-esteem so that they would be more eager to learn and to ask for assistance in need.

The other 3 English teachers mentioned their own ways to guide and monitor the students' independent work. One of them liked to sit in the students' groups to discover more about the students' learning process and to become closer to the students since teacher must also build good relationship with each student. Another one liked to find a spot where the students' activities could be seen; usually it would be in the corner of the classroom. The rest would sometimes invite the students to come in front and delivered their answers or works. In this 
way, the teachers gave feedback which weren't only for the students sharing their answers, but also for the whole students in the classroom.

\section{Checking for students' understanding}

Besides guiding the students' independent works, the English teachers were also regularly checking the students' understanding about the materials taught and practiced. There were many activities done by the English teachers to confirm the students' understanding.

It's showed in Chart 8. that the three best activities done by the English teachers to check the students' understanding were giving questions and asking the students to answer it orally together, conducting a small quiz, and giving questions and asking the students to answer it in a piece of paper which was submitted. Then, the following choices were asking the students to summarize the main points of the materials taught, conducting games related to the materials, and directing the students to do particular online exercises.

Chart 8: Ways of Checking the Students' Understanding

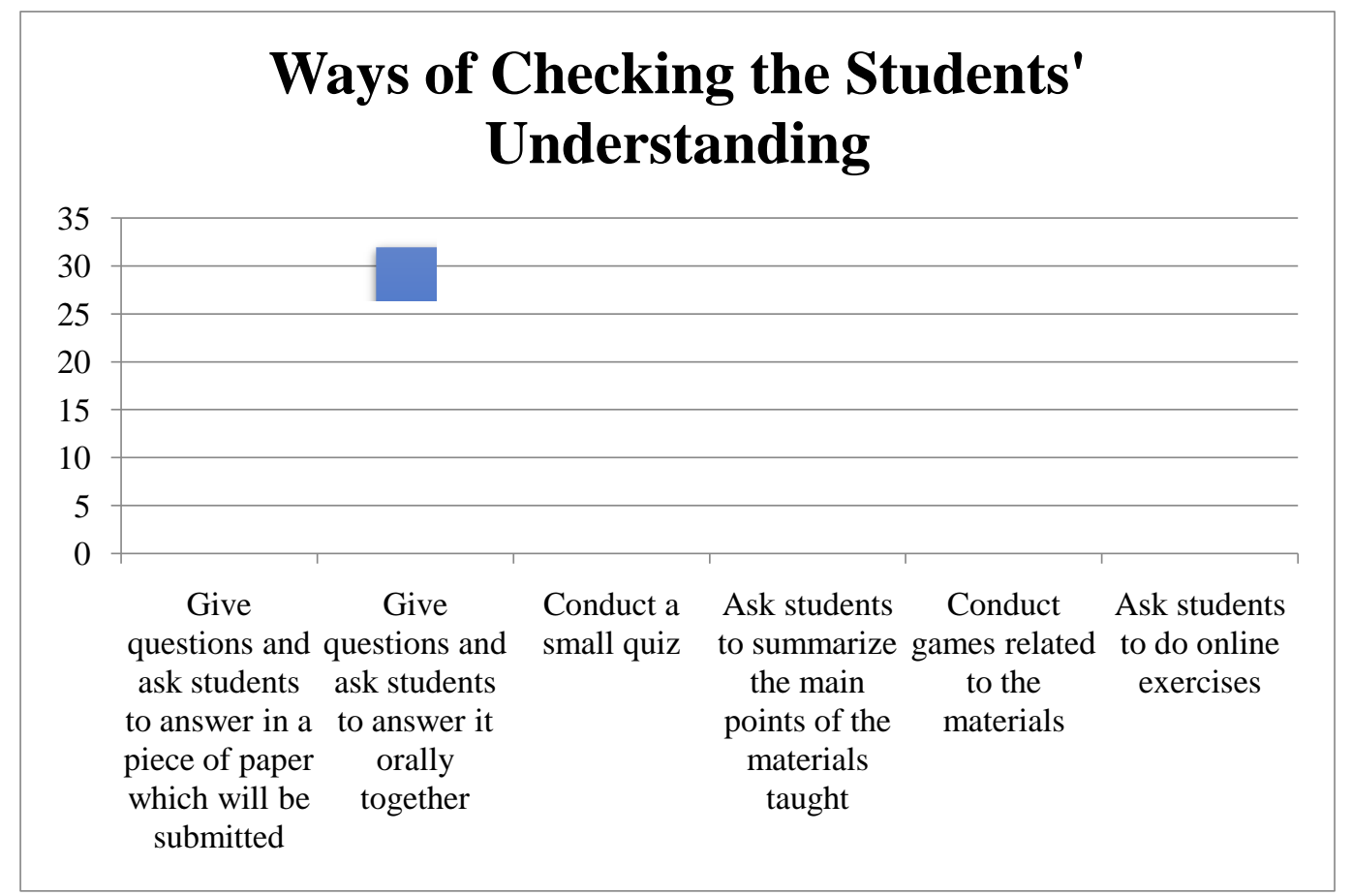

From 95 answers, $33.7 \%$ of them preferred to give questions and ask students to answer it orally together so that the English teachers ensured that every single student had understood the materials. $29.5 \%$ of the answers liked to conduct a small quiz so the students would be more familiar with the form of the test of the materials. Similar to that, $17.9 \%$ of the answers showed that the English teachers liked to give questions and ask the students to answer it in a piece of paper which was submitted and being checked by the teachers. This way, the teachers had a concrete evidence of the students' understanding and could know whoever students didn't understand certain parts of the materials. $16.8 \%$ of the answers displayed that the English teachers also asked the students to summarize the main points of the materials taught so that the students narrowed down the 
whole explanation and activities done during the meeting and were able to take important points of the materials taught.

Two English teachers mentioned their own experience in checking the students' understanding. One of them conducted games related to the materials to deepen the students' understanding and encourage the students to apply the theories of the materials to some fun games. That games and fun activities were more memorable was believed as the goal of strengthening the materials in the students' long-term-memory. Another English teacher related the technology product which was online exercises as the source for the students to easily check their own understanding. The teacher showed the students that there are so many learning sources beside textbooks and the teacher him/herself. This way, the students could enlarge their knowledge of getting learning sources from the internet which is accessible for their independent learning at home or wherever they are.

\section{Scaffolds for difficult tasks}

In giving difficult tasks for the students, it's essential for the teachers to provide scaffolds. The goal is for the students to be equipped and guided in their learning process.

Chart 9: Scaffolds Provided for Difficult Tasks

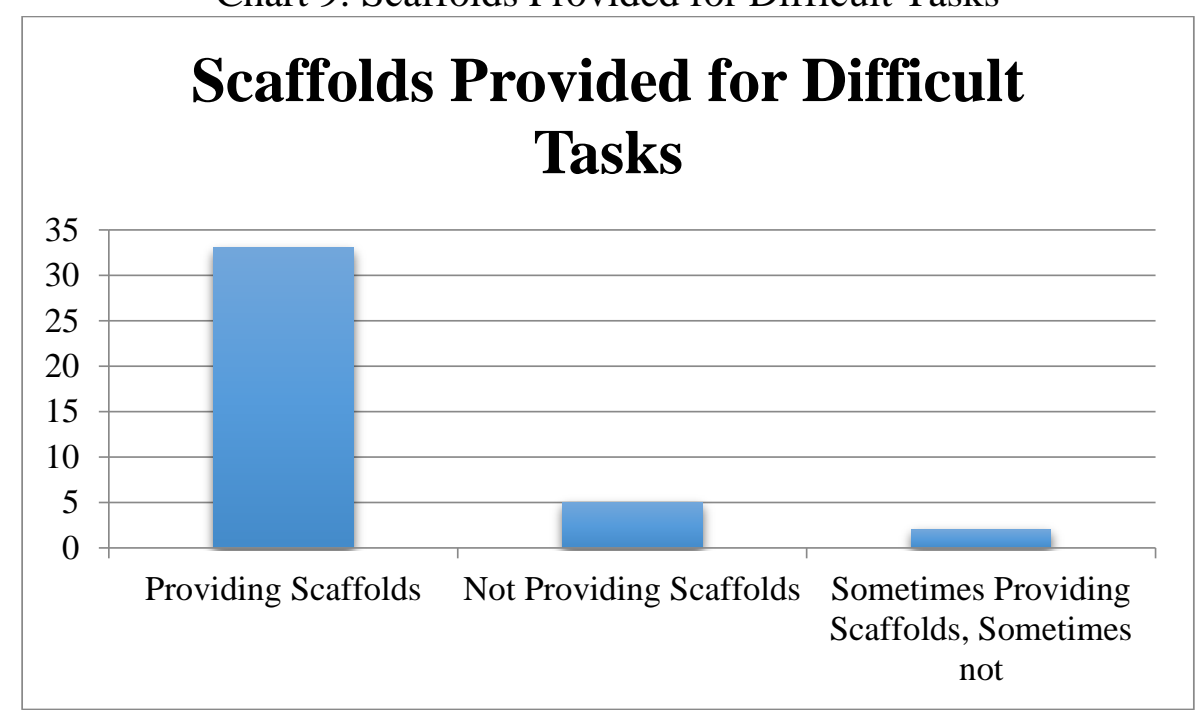

In the chart above, $82.5 \%$ of the respondents stated that they provided scaffolds for the difficult tasks given to the students. They believed that with the proper scaffolds and guides, they could maintain the students' learning process so that whenever the students found difficulties and made errors, the teachers were ready to give the correct answers or any other helps. 5\% of the English teachers mentioned that sometimes they provided scaffolds only if the tasks' difficulty was twice or above of the students' capability. The rest of the English teachers gave more trust on the students to explore by themselves and struggle in finding the best solutions for the difficult tasks without any scaffolds provided. The hard process of finding the solutions was believed to leave a long term memory for the students. That the teachers were only monitoring the students' works was believed 
to be a great opportunity for the students to think more critically and independently.

\section{Requiring and monitoring independent practice}

Instead of only giving the students practices inside the classroom, the teachers had to give many other exercises outside the classroom. The students needed extra practices in order to train themselves in mastering the materials. Various kinds of practices were constructed and given to the students as their assessment and homework. The students might work in groups, with peers, and individually according to the teachers' instructions.

Chart 10: Independent Practices Assessed to the Students

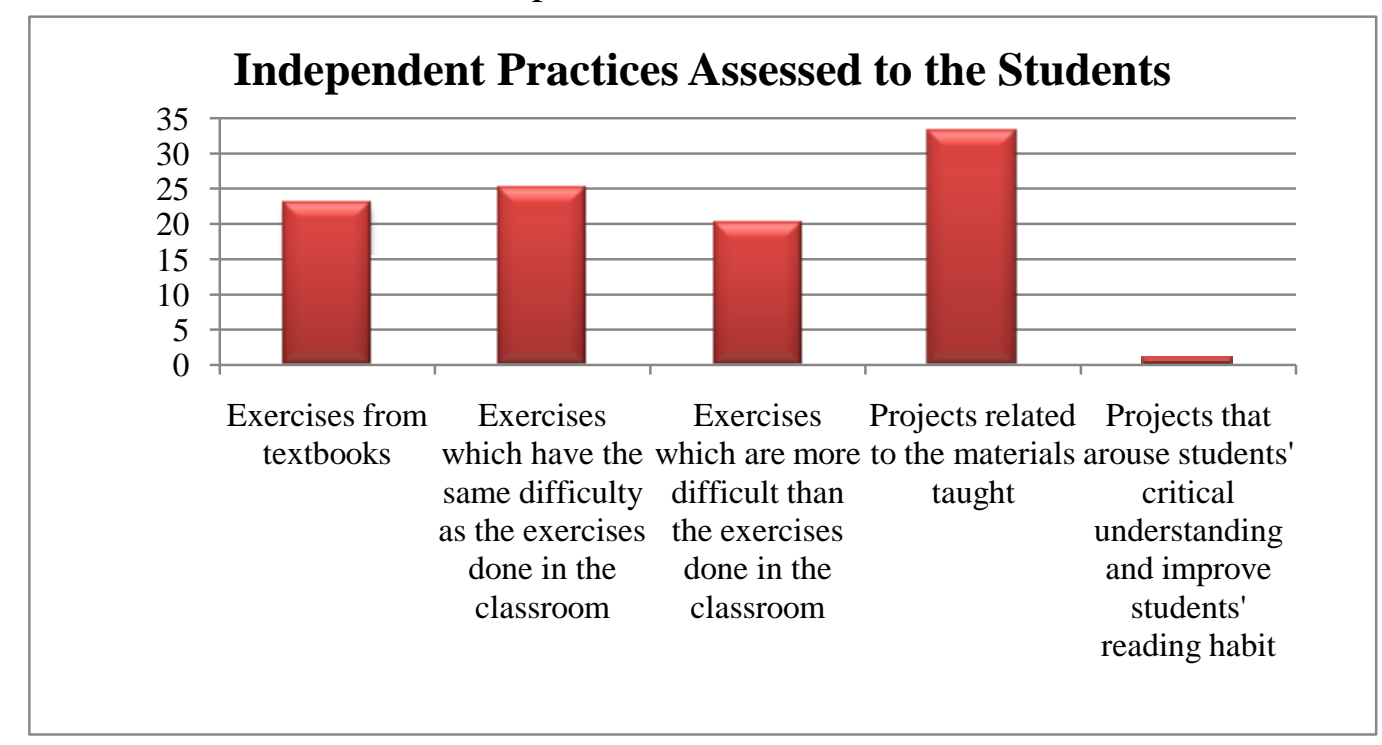

33 out of 103 answers showed the English teachers enjoyed to assess projects to the students. The projects were formed in texts, essays, field reports, short movies, and many others done in groups, peers, or individual. 25 answers displayed that the English teachers liked to assess the students to do exercises which are the same difficulty as the exercises had done in the classroom to drill the students' ability about the materials. Slightly different, 23 answers displayed that the English teachers leaned on the exercises constructed in the textbooks used in the classroom. In the following meeting, the exercises in the textbooks then were checked together or were submitted to be checked and scored by the teacher themselves. 20 answers showed that the English teachers constructed and assessed the students' exercises which were more difficult than the exercises done in the classroom. The goal was for the students to improve their mastery of the materials by exploring more difficult exercises. Other two answers mentioned that the English teachers had their own way to assess the students by constructing more complex projects and the focus were for the students to arouse their critical understanding and improve their reading habits. 


\section{Conducting weekly and monthly review}

Over learning the materials taught was very beneficial for the students to be ready in facing any tests or exams. This could be done by conducting the review monthly or weekly beside the review done in the beginning of the meeting. As a result, the students weren't burdened to study in such a short time before any tests or exams since they've been reviewed about the whole materials. The review done by the teachers varied in several different ways. Most of them reviewed the materials once in a month and once before the final exam. However, there were some English teachers conducting the review as many as the students needed. The detailed data could be seen in Chart 11 below.

Chart 11: Review Done besides the Every Meeting Review

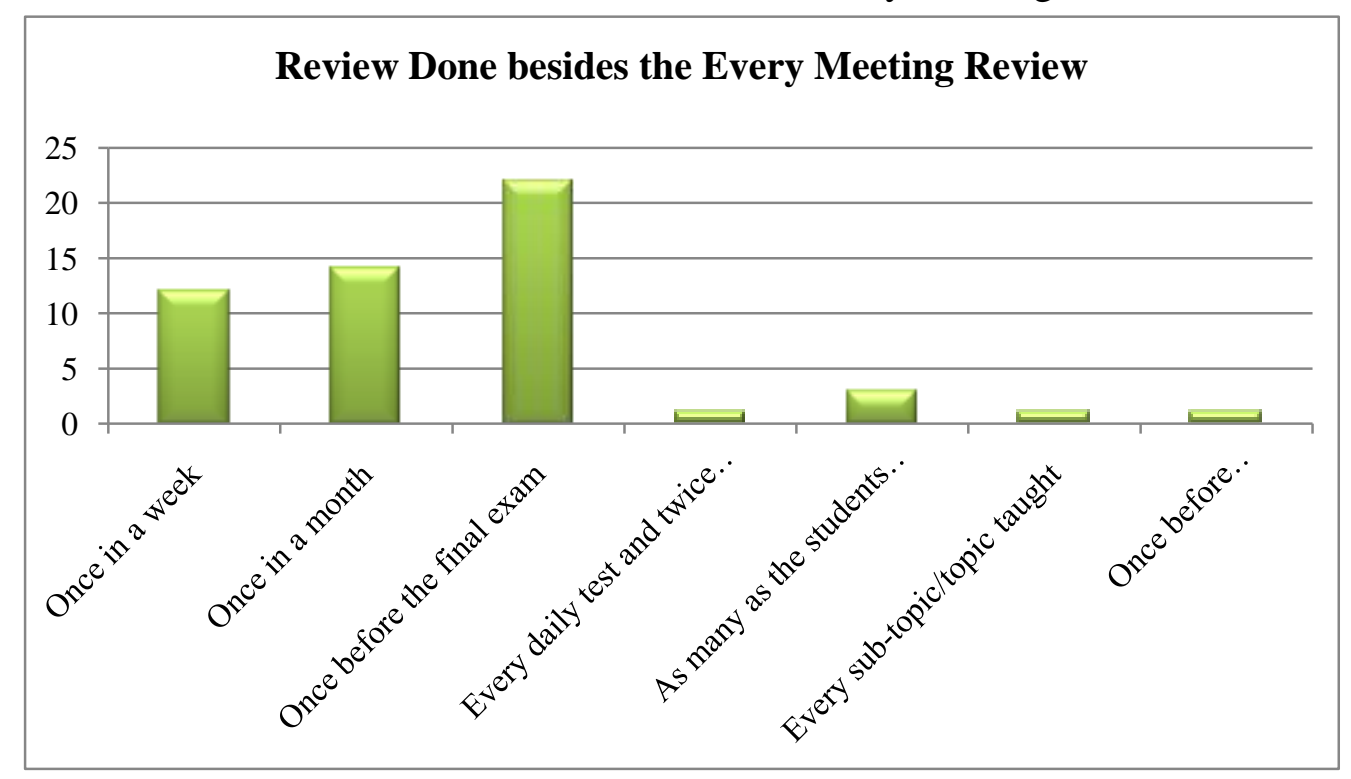

From 54 answers, $40.7 \%$ of them showed that the English teachers liked to conduct the review once before the final exam so the students' memory of the materials was still fresh and the students felt more ready to face the final exam. $25.9 \%$ of the answers presented that the English teachers liked to do the review monthly and $22.2 \%$ of them weekly. $5.6 \%$ of the answers revealed that the English teachers willingly reviewed and re-taught the materials whenever the students needed. They often asked the students' understanding and re-taught the materials directly when the students couldn't comprehend the materials well.

The rest of the answers discovered the English teachers' own way to review the materials for the students. One of them always reviewed the materials once before the daily tests and twice before the mid-term and final-term test. Another one preferred to conduct the review directly after explaining a sub-topic. The rest liked to conduct the review once before formative test, mid-term test, and final-term test. 


\section{Treat the Students Who Fail to Meet the Minimum Criterion of Mastery Learning}

As showed in Table 12 not all of the students met the Minimum Criterion of Mastery Learning (MCML). To contend those students who couldn't fulfill the MCML, the teachers took some proper ways based on the school's regulations and the students' needs. They sometimes gave remedial tests to the students until the MCML was fulfilled, took students' assessment points for their additional points, assessed the students with individual project to be the students' additional points for the assessment and many other due to the teachers' choices.

Chart 12: Actions Taken to Treat the Students who fail to meet the MCML

\section{Actions Taken to Treat the Students who Fail to Meet the MCML}

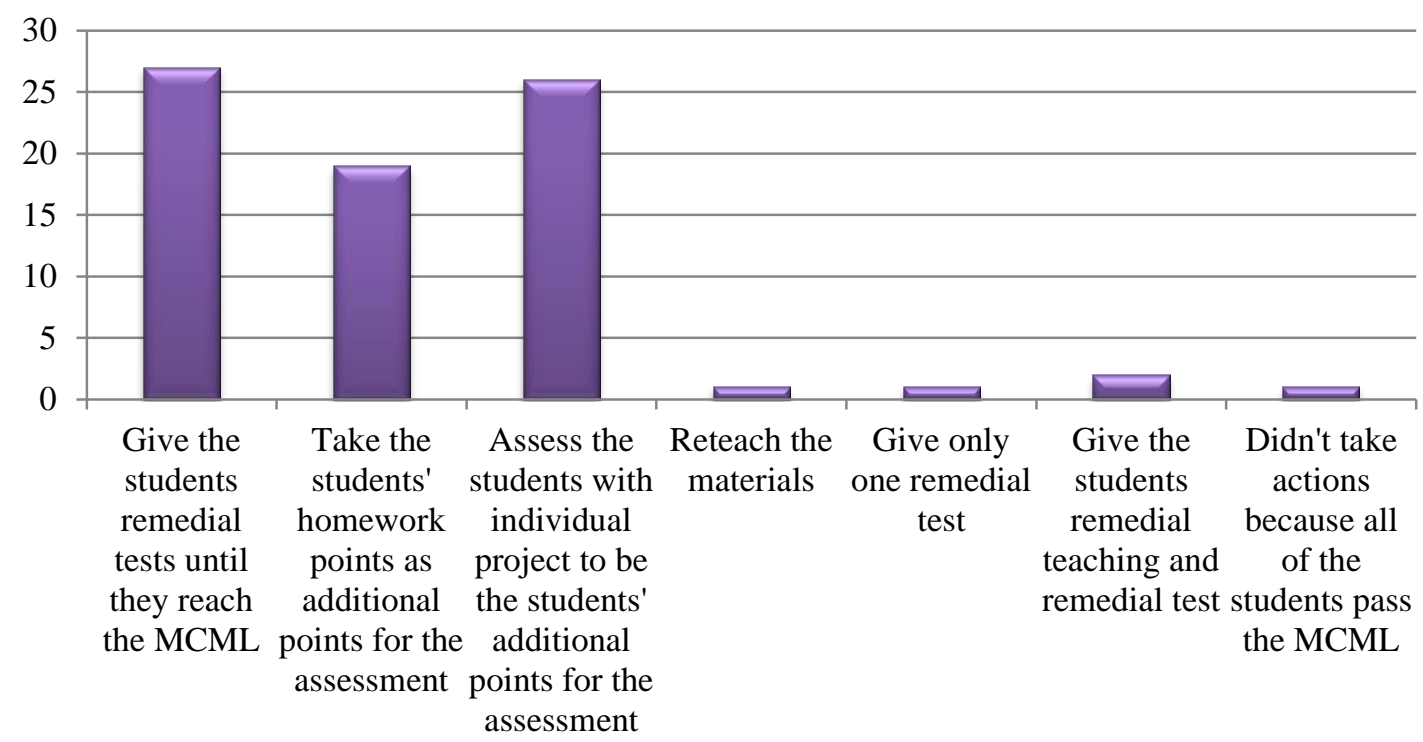

27 out of 77 answers showed that the English teachers gave the remedial tests for the students to meet the MCML. Similarly, 26 of the answers displayed that the English teachers assessed new individual project for the students and the score later was taken for the students' additional points. 19 of the answers showed that the existed assessment points could be taken by the English teachers for the students additional points. One answer displayed that the English teacher only gave one more chance for the students to have remedial test so that the students tried their best in that only one remedial test. Instead of giving remedial test, 1 answer showed that re-teaching materials for the students also mattered. Other 2 answers mentioned that the English teachers did both re-teaching the materials and giving the remedial test for the students so that the students understood more about the materials before being assessed for the second time. Only 1 English teacher who didn't do any remedial test for the school didn't allow the teachers to do so. 


\section{The English Teachers' Perception of Minimum Criterion of Mastery Learning}

Each school applied different MCML for English subject. From the questionnaires, it's found that the most applied MCML for English subject was 75 ; then followed by 70,67 , and 80 for the least.

Chart 13: MCML for English Subject in each School

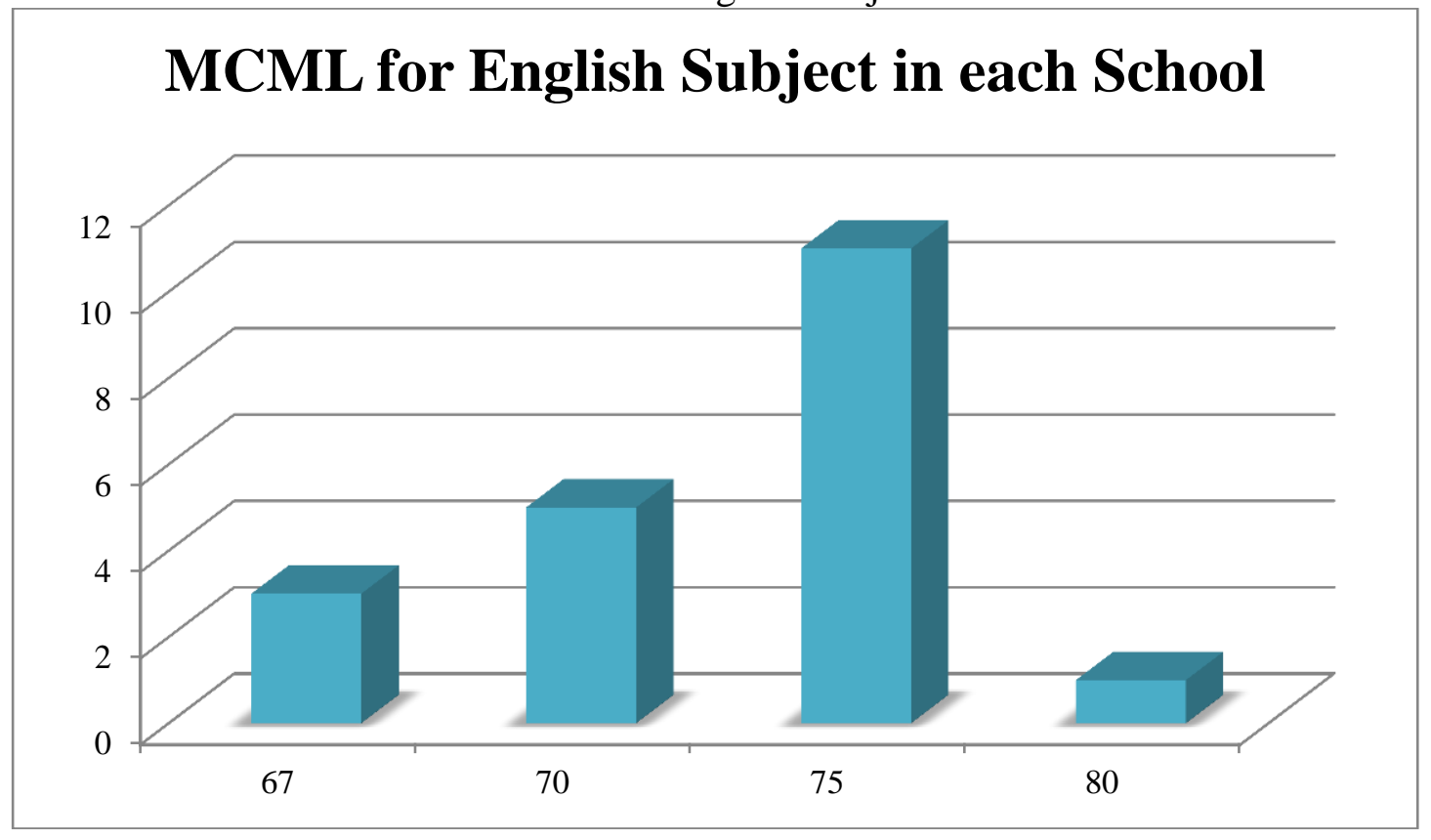

40 English teachers were teaching in 20 schools with 3 different levels; those were 7 Junior High Schools, 12 Senior High Schools, and 1 Vocational High School. From those 20 schools, 11 schools applied 75 as the MCML of their English subject. 5 schools used 70 as the MCML of their school. 67 was used as the English subject's MCML and only one school used 80 for the MCML of the English subject.

MCML was decided by the Education Authorities (School Principal, Vice Principals, and Teachers) of each school. There were various considerations determining the applied score for the MCML of English subject. The considerations were the policy of the government, the students' achievement level in the school, the teachers' capability and mastery, the schools' facility and the lesson's difficulty. The detailed data could be seen in Chart 4.14. 
Chart 14: The Factors Determining the MCML

\section{The Factors Determining the MCML}

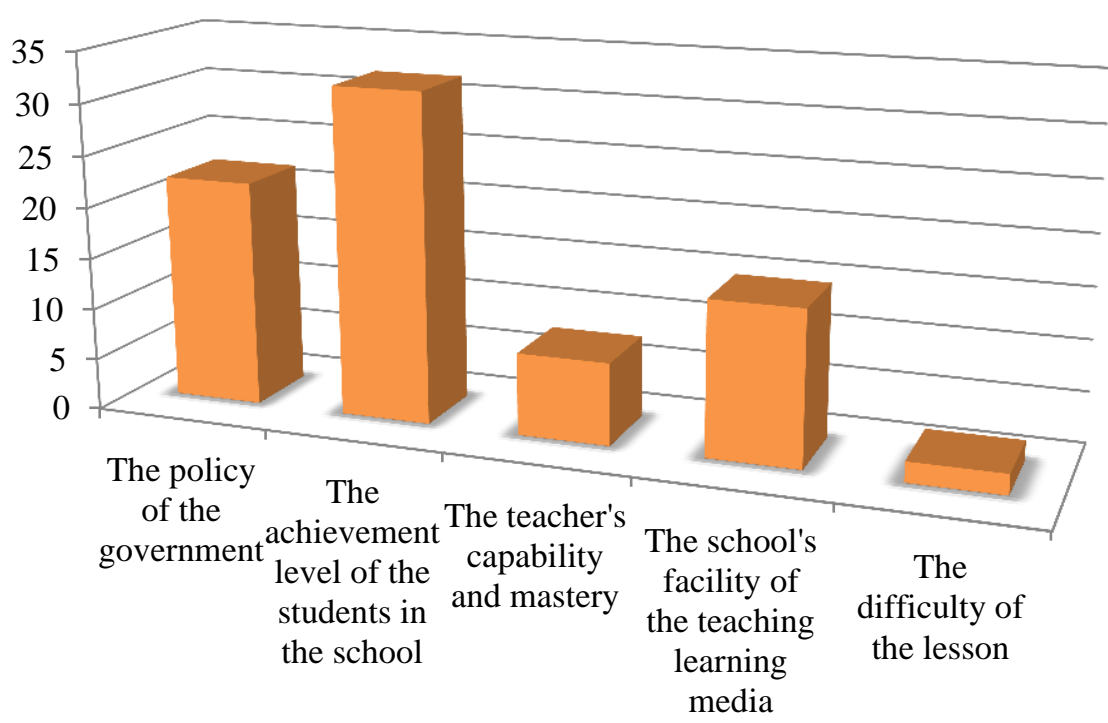

In this question, the respondents might choose more than 1 answer so the answers collected were 79 answers. The achievement level of the students in school appeared to be the highest consideration for the Education Authorities to determine the MCML with the percentage of 40.5\%. The second highest consideration was the policy of the government with the percentage of $27.8 \%$. Then, $19 \%$ of the answers showed that the Education Authorities also considered the school's facility and learning media which support the students' learning process. $10.1 \%$ of the answers displayed that the Education Authorities considered the teacher's capability and mastery of the materials to teach them to the students. The difficulty of the lesson appeared to be least consideration of the Education Authorities in determining the MCML with the percentage of $2.5 \%$.

The MCML was very essential for the English teachers as the standard of the students' mastery. It showed clearly that if the students passed the MCML, they mastered the materials, and vice versa. Yet, not all of the English teachers thought the same way. 
Chart 15: The English Teachers' Perceptions of MCML

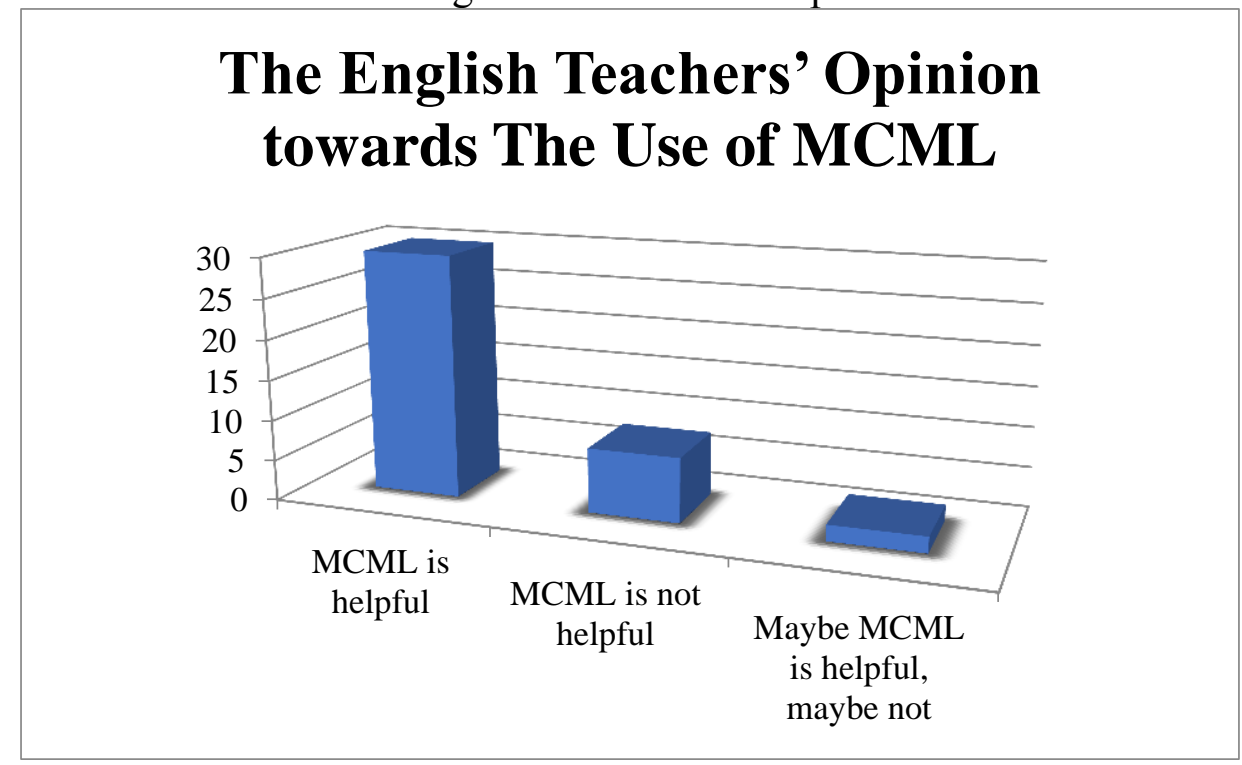

30 English teachers agreed that MCML was helpful for them as the standardized rules of mastering particular materials. 2 English teachers weren't sure about the usage of MCML since they thought the teaching learning activities and process were more crucial and important. 8 English teachers disagreed that MCML was beneficial for both the students and themselves. The reasons were that the students only focused in mastering the materials explained and taught in the classroom so that they passed MCML in the exams rather than exploring the elaboration of the materials in their daily life. Even most of the students directly forgot the materials soon after the exams done since they worked in mastering the materials few days before the exams just to pass the MCML without considering putting the materials in their long-term-memory.

\section{DISCUSSION}

As stated in Chapter Two that curriculum is the total activities of the students occur in the educational process arranged by a formal institution. Curriculum consists of a planned sequence of instruction, goals, the standard of the competency, the process standard and the teaching learning process. The whole curriculum is constructed by the Ministry of Education and Culture. The standard of the students' learning mastery then is defined by a criterion called Minimum Criterion of Mastery Learning (MCML). To fulfill the MCML in English subject, the students depend on the teachers' capability in managing the curriculum and constructing effective teaching learning activities. Thus, the teachers used Instructional Strategies that were used to plan and construct the whole teaching learning activities and process. One of the Instructional Strategies mostly used by the English teachers in Indonesia was 10 Research-based Principles of Instructional Strategies mentioned by Rosenshine (2010).

The writer then researched whether the English teachers in Surabaya had already used the 10 Research-based Principles of Instructional Strategies mentioned by Rosenshine (2010) in assisting the students to meet the MCML. The research was done by distributing questionnaire to 40 English Teachers and 
interviewing 20 English teachers to discover wider experiences and strategies used by them.

From the questionnaires, it is found that $75 \%$ of the respondents agreed that MCML was helpful for the students as the standard of the students' mastery in certain materials. Beside the facts that MCML also gave bad impacts for the students in their learning process in facing tests and in their social life, most of the teachers still could accept that MCML supported them to know whether the students have mastered the materials or not. The respondents also mentioned several considerations the Educational Level used to determine the MCML. From 20 different secondary level schools, 55\% of them applied 75 as the MCML for their English subject. Then, it's followed with 70 with the percentage of $25 \%$; 67 with the percentage of $15 \%$; and 80 with the percentage of $5 \%$.

The number of the considerations used to determine the MCML was also varied according to each school's regulations and decisions. $40.5 \%$ of them agreed that the achievement level of the students in the school was the most important thing among other factors. The Education Authorities considered that if the MCML applied was too high, then the students wouldn't be able to reach it and the students' record appeared to be not satisfying. Besides, it'd give another impact to the students since they would feel being burdened with such a high MCML that they had to fulfill. The least consideration was the difficulty level of the school with the percentage of $2.5 \%$ of the answers. The difficulty level depended more on the teachers' capability and mastery in developing and modifying the materials so that the students could comprehend it more easily.

Although each school applied different score as the English subject's MCML, the English teachers of those schools were using very similar Instructional Strategies. Almost all of the principles were used by the respondents to assist their students in meeting the MCML. Some others also mentioned their experiences in supporting the students' learning process so that MCML was passed.

At the beginning of the lesson, $82.5 \%$ of the respondents conducted review of the previous materials. The reasons were because (1) the students' focus needed to be attracted so that the students could direct their mind into the English subject, (2) the day's materials were connected to the previous materials, and (3) the teachers wanted to check the students' memory of the previous materials so that the students wouldn't easily forget the materials as later they should master the whole unit. Only $2.5 \%$ of the answers mentioned that the respondents didn't conduct the review since most of the materials in each meeting weren't related to the previous materials and the review would be done at the end of the whole unit.

In 1 meeting which consisted of 80-90 minutes, the respondents used their time maximally for the students to learn, discover, and drill themselves with the materials. $68.1 \%$ of the answers displayed that the respondents explained 1 subtopic only in 1 meeting and trained the student with practices related to the materials so that the materials was being in the students' long-term memory. Only $8.5 \%$ of the answers showed that the respondents preferred to encourage the students to use most of the time for exploring the materials themselves with the teacher's supervision. The teachers only use 20-30 minutes to explain or give feedback to the students' work. The students got such a big opportunity to explore and discover many things related to the materials explained and to their 
background knowledge. It meant that they could enrich their knowledge more by solving the new materials themselves.

In strengthening the students' learning process, $63 \%$ of the respondents stated that they often delivered questions to the students after explaining something. The teachers showed the students' needs to be confirmed while they comprehended particular materials. Asking questions at the beginning of the lesson seemed to be the least important thing with the percentage of $1.9 \%$ since the teachers preferred to give information about the new materials first before asking any questions to the students. Two types of questions, CCQ (Concept Check Questions) and ICQ (Instructional Check Questions), were used equally in different times. 95\% of the answers showed that the respondents used the CCQ after explaining certain materials and ICQ after giving instructions of any activities or exercises. 2.5\% liked to use more CCQ and another 2.5\% liked to use more ICQ. For the function was related to each other, both CCQs and ICQs used had to be balanced so that the students could comprehend every materials and instructions delivered and the teaching learning process ran well.

In giving the students' independent practices, only $2.5 \%$ didn't give any models. The reason was that the teacher wanted the students to be very independent in finding a solution for the problem. While most of the answers agreed to give models or examples for the students' first step before they could do the exercises by their own, with the percentage of $87.5 \%$.

Providing models were defined by the teachers' teaching styles. $44.4 \%$ of the answers stated that the respondents agreed to provide models for the students by doing the exercises together with the students. In this way, the students felt more comfortable and confident in answering the questions since they were accompanied by the teachers. They didn't seem to be afraid and embarrassed of the mistakes they made. Then, it's followed by the way of giving a correctly answered exercise for the students' model in practicing. The students then were able to do self-checking when they compared their answers with the correctly answered one even if they couldn't check all numbers. Doing the exercises alone on the board and asking the students to observe only got $15.3 \%$ since the students didn't get involved in it and the teacher-centered teaching style became appeared.

While the students were practicing, $76.9 \%$ of the respondents were walking around the classroom and observing the students' works. By walking around the classroom, the students erased the distance between the teachers and the students. The students also felt being cared by the teachers since the teachers liked to visit them and were ready to be asked about anything related to the materials or exercises. 3 respondents mentioned their own experiences that they preferred to sit in groups and talk to each student one by one while they're practicing, stood at the corner of the classroom to monitor the students' work, and asked the students to come in front and the teacher was somewhere at the back of the class listening to the students coming in front.

The students' focus and understanding could be blown away if they were not maintained and checked. Therefore, the English teachers had to construct so many ways in checking the students' understanding of the materials taught. 29.5\% of the answers displayed that the respondents preferred to conduct a small quiz as the evidence of the students' understanding. The word 'quiz' itself made the students worried and struggle to cheat. So, they depended on their own 
understanding of the materials and the answers of the quiz then were valid for the teachers to score to determine whether the materials had to be retaught or not. $1.1 \%$ of the answer showed the least activities that the respondents did to check the students' understanding, which were conducting games and accessing online exercises. The teacher believed that conducting fun games could support the materials to be left in the students' long-term memory since students preferred games than lectures. Besides textbooks and teachers' exercises, online exercises were also very helpful to check students' understanding since the students could answer them more easily and practically and the teachers could also check the answers effectively.

Tasks given to the students were also varied in their difficulty level. When the teachers gave a difficult task, they also had to provide scaffolds to support the students' learning process. However, $12.5 \%$ of the answers presented that some respondents weren't providing any scaffolds since they wanted to trust the students more and they needed to show the students that they trusted the students. Therefore, the teachers focused on encouraging the students' self-confidence and self-esteem in exploring the materials and relating them to their background knowledge or daily life. The other $82.5 \%$ of the answers showed that the respondents preferred more to provide scaffolds for the students' difficult task.

Many independent exercises were assessed to the students to drill their learning mastery at home. The most favorable task was giving projects to the students. The projects could be formed in making a short movie, reading fiction or scientific books in English, creating a mini performance (video clip, musical drama, poems reading, to be presented, etc.) and writing essays (about song/movie analysis, social experiment report, present accidents/news item, observation, interview result, etc.). That the students could do the projects individually or in team depended on the teachers' decision with the consideration of the task's difficulty.

Beside the review done at the beginning of the lesson, the students needed more reviews to support their memory of the materials taught. The students were studying more than 1 subject in school. Therefore, the teachers understood that the students often forgot about the materials. Hence, $40.7 \%$ of the teachers were willingly conducting reviews before the final exam so that the students became more ready in facing the exams. $25.9 \%$ of the teachers conducted the review monthly and $22.2 \%$ of them weekly. They spared the time so that the students could really comprehend the whole materials before being assessed in the midterm and final-term test.

All of those Instructional Strategies applied and done in the classrooms were proven to support enough the students in meeting the MCML. It could be seen by the number of the students passing the MCML in the 20 schools. $75.7 \%$ of the students were recorded to be successfully passing the MCML for the teachers had assisted them with the planned Instructional Strategies.

The other $24.3 \%$ of the students failed in passing the MCML were treated with various ways. The most preferable action taken by the teachers was assessing the students with individual project to be the students' additional points for the assessment. This action was taken because the project done by the students were also the evidence of the students' learning mastery. The second favorable action was giving the students remedial test until they reach the MCML, with the 
percentage of $35 \%$ of the answers. $2.6 \%$ of the answers showed that the teachers equipped the students with remedial teaching right before the students were being assessed in the remedial test so that the students' understanding of the mastery would be refreshed again. Only $1.3 \%$ of the answers showed that the teachers didn't do any remedial test since the school's regulations didn't allow any remedial test to be conducted.

In sum, the 10 Research-based Principle of Instructional Strategies by Rosenshine (2010) appeared to be proportionate representatives of the whole activities and strategies used by the English teachers in assisting the students to meet the Minimum Criterion of Mastery Learning. In addition, the English teachers could take students' project points as the additional points, conduct remedial teaching, and remedial tests for contending the students who fail in meeting the Minimum Criterion of Mastery Learning.

\section{CONCLUSION}

Many activities were planned by the English teachers to assist the students to meet the MCML. 10 Research-based Principles of Instructional Strategies by Rosenshine (2010) appeared to be the appropriate representatives of the whole activities done by the English teachers inside the classroom. 82.5\% of the English teachers conducted review at the beginning of the meeting and $68.1 \%$ of them agreed that they explained the materials in certain sub topic step-by-step in 1 meeting. $63 \%$ of the English teachers delivered a large number of questions to the students and both ICQ and CCQ were delivered equally by $95 \%$ of the English teachers. Models for the students in doing practices were provided by $87.5 \%$ of the English teachers and $44.4 \%$ of them provided the models by doing the exercises together with the students. While the students were practicing exercises, $76.9 \%$ of the English teachers were guiding them by walking around the classroom to monitor the students' works and being flexible for the students when they needed assistance from the teachers. That checking the students' understanding mattered was shown by $33.7 \%$ of the English teachers who agreed that they gave questions and asked the students to answer them orally together so that the teachers knew the students' understanding. That $75.7 \%$ of the students taught by the English teachers met the MCML displayed that the English teachers obtained high success rate for the students' learning mastery. Scaffolds were provided by $82.5 \%$ of the English teachers in order that the students were guided and supported while they were doing difficult tasks. 32\% of the English teachers agreed to give projects related to the materials as the students' independent practice since the projects could be varied depended on the teacher's decision and plan. In addition, besides the review done at the beginning of the meeting, $40.7 \%$ of the answers displayed that the English teachers were conducting review of the whole materials taught before final exam. As the main percentage, $65.2 \%$ of the answers presented that the English teachers used the 10 Research-based Principles of Instructional Strategies mentioned by Rosenshine (2010).

Finding out the students' learning mastery, the English teacher's next job was to take actions to treat the students who failed to meet the MCML. 35\% of the answers presented that the English teachers gave the students remedial tests until they reached the MCML which meant that the students were assessed again until they comprehended the materials well. 
Therefore, it can be concluded that the 10 Research-based Principles of Instructional Strategies are appropriate to be included in the English teachers' strategies in assisting the students to meet the Minimum Criterion of Mastery Learning. Furthermore, the English teachers could be more creative in constructing and planning effective activities for the students to meet the Minimum Criterion of Mastery Learning.

\section{REFERENCES}

Airasian, P.W. (1991). Classroom assessment. USA: McGraw-Hill, Inc.

Alberta. (2002). Instructional strategies. Retrieved from https://education.alberta.ca/media/482311/is.pdf on $28^{\text {th }}$ January 2018.

Azis, Astuti. (2014). Indonesian junior secondary school teachers' conceptions of assessment: A mixed methods study. Doctor of Philosophy in Education, Victoria University, Wellington, New Zealand.

Brown, H. D. (2004). Language assessment: Principles and classroom practices. United States: Pearson Education, Inc.

Kementrian Pendidikan dan Kebudayaan (The Ministry of Education and Culture). (2016). Panduan penilaian oleh pendidik dan satuan pendidikan untuk sekolah menengah atas [Scoring guidance for the secondary high schools by the educators]. Jakarta: Depdikbud.

Kementrian Pendidikan dan Kebudayaan (The Ministry of Education and Culture). (2016). Panduan penilaian oleh pendidik dan satuan pendidikan untuk sekolah menengah pertama [Scoring guidance for the junior high schools by the educators]. Jakarta: Depdikbud.

Kementrian Pendidikan dan Kebudayaan (The Ministry of Education and Culture). (2016). Standar proses pendidikan dasar dan menengah [The standard of the primary and secondary educational process]. Jakarta: Depdikbud.

Rosenshine, Barak. (2010). Principles of instruction. USA: International Academy of Education. Retrieved from www.unesco.org/fileadmin/user_upload/Publications/EducationalPractices /EdPractices_21.pdf on $29^{\text {th }}$ January 2018.

Thomas, Ingrid A. (2015). Using instructional strategies to enhance student achievement. Department of Leadership \& Policy Studies, College of Education, University of Memphis, Memphis, TN.

Utami, Rahmawati. (2013). Implementasi standar penilaian KKM dalam pencapaian hasil belajar PKN siswa di SMP Negeri 3 Minas Kec. Minas $K a b$. Siak. Department of Civics, Riau University, Riau, Indonesia. 